\title{
Novel Antihypertensive Lactoferrin-Derived Peptides Produced by Kluyveromyces marxianus: Gastrointestinal Stability Profile and in vivo Angiotensin I-Converting Enzyme (ACE) Inhibition
}

Aurora García-Tejedor, ${ }^{\dagger}$ Laura Sánchez-Rivera, ${ }^{\ddagger}$ María Castelló-Ruiz,,${ }^{\S} \|,{ }^{\perp}$ Isidra Recio, ${ }^{\ddagger}$ Juan B. Salom, ${ }^{\S} \|, \perp$ Paloma Manzanares *,

†Departamento de Biotecnología de Alimentos, Instituto de Agroquímica y Tecnología de Alimentos, Consejo Superior de Investigaciones Científicas (IATACSIC), Ave Agustín Escardino 7, 46980 Paterna, Valencia.

‡Instituto de Investigación en Ciencias de la Alimentación. Consejo Superior de Investigaciones Científicas-Universidad Autónoma de Madrid (CIAL, CSICUAM). Nicolás Cabrera 9, 28049, Madrid, Spain.

§Centro de Investigación, Hospital Universitario 'La Fe', Ave. Campanar 21, 46009, Valencia, Spain.

\|Departamento de Fisiología, Universidad de Valencia, Ave. Blasco Ibáñez 17, 46010, Valencia, Spain.

${ }^{\perp}$ Unidad Mixta de Investigación Cerebrovascular, Fundación Investigación Hospital La Fe - Universidad de Valencia, Valencia, Spain.

${ }^{*}$ Corresponding author: Tel.: 34-96-3900022; Fax: 34-96-3636301; e-mail address: pmanz@iata.csic.es 


\section{Abstract}

2

Novel antihypertensive peptides released by Kluyveromyces marxianus

3 from bovine lactoferrin (LF) have been identified. K. marxianus LF permeate was

4 fractionated by semi-preparative high performance liquid chromatography and 35

5 peptides contained in the angiotensin I converting enzyme (ACE)-inhibitory

6 fractions were identified by using an ion trap mass spectrometer. Based on

7 peptide abundance and common structural features, six peptides were

8 chemically synthesized. Four of them (DPYKLRP, PYKLRP, YKLRP and GILRP)

9 exerted in vitro inhibitory effects on ACE activity and effectively decreased

10 systolic blood pressure after oral administration to spontaneously hypertensive

11 rats (SHRs). Stability against gastrointestinal enzymes suggested that the

12 sequence LRP could contribute to the in vivo effects of parental peptides. Finally,

13 there were reductions in circulating ACE activity and angiotensin II level in SHRs

14 after either DPYKLRP or LRP intake, thus confirming ACE inhibition as in vivo

15 mechanism for their antihypertensive effect.

17 Keywords: Kluyveromyces marxianus, lactoferrin-derived peptides, 18 gastrointestinal digestion, antihypertensive effect, in vivo ACE inhibition. 


\section{INTRODUCTION}

In the last decade much work has been done to characterize the antihypertensive effects of peptides derived from food proteins. ${ }^{1}$ Angiotensin Iconverting enzyme (ACE) inhibition is the main target for those peptides. ACE, as part of the renin-angiotensin system (RAS), hydrolyzes both the inactive angiotensin I into vasoconstrictor angiotensin II and the vasodilator bradykinin into an inactive peptide leading to blood pressure upregulation. ${ }^{2}$ In vitro inhibitory effect of food protein derived peptides on ACE activity is well established in contrast with the limited in vivo evidence available for the mechanism of action underlying their blood pressure lowering effect. Also bioavailability of ACEinhibitory peptides has been intensively studied since it is known that bioactive peptides may undergo physiological transformations that determine their activity in the organism. ${ }^{3}$ Most research has been focused on milk derived antihypertensive peptides, some of which have shown beneficial effects in clinical assays, as reported in different meta-analyses. ${ }^{4}$

The use of the proteolytic system of lactic acid bacteria (LAB) to hydrolyze milk proteins is a successful strategy to release antihypertensive peptides. ${ }^{5}$ By contrast few studies exploit the proteolytic potential of yeasts despite their contribution to proteolysis in dairy products is well established. In this context, the lactose-fermenting yeast Kluyveromyces marxianus regularly found in milk and dairy products has been pointed out as a promise candidate to generate antihypertensive peptides from the whey proteins $\alpha$-lactalbumin and $\beta$ lactoglobulin. ${ }^{6}$ Its potential to produce fermented milk with casein-derived ACEinhibitory peptides has been also described ${ }^{7}$ although in vivo antihypertensive effects were not evaluated in any of these reports. 
Bovine lactoferrin (LF), a well-characterized component of milk whey, is also a good source of antihypertensive peptides. We have shown that enzymatic LF hydrolyzates lower blood pressure and thus exhibit potential as orally effective antihypertensive compounds. ${ }^{8,9}$ Moreover, after long-term intake of a pepsin LF hydrolyzate, there were reductions of circulating ACE activity, angiotensin II and aldosterone levels, as well as a compensatory increase of renin activity. ${ }^{10}$ So far, only five LF-derived peptides with sequences RRWQWR, WQ ${ }^{11}, R P Y L, L I W K L$ and LNNSRAP ${ }^{8}$ have shown antihypertensive effects after oral administration to spontaneously hypertensive rats (SHRs), although based on in silico studies some other antihypertensive peptides are expected to be still identified and isolated from LF hydrolyzates. ${ }^{12}$

In a previous work, proteolytic yeast strains of Debaryomyces hansenii, Kluyveromyces lactis and $K$. marxianus isolated from cheeses ${ }^{13}$ were screened for their ability to grow in media with LF as sole nitrogen source and to produce LF hydrolyzates containing ACE-inhibitory peptides. K. marxianus $\mathrm{Km} 2$ strain grown on LF produced the most potent hydrolyzate which, when orally administered to SHRs, exerted antihypertensive effect. ${ }^{14}$

The objective of the present study was to identify the LF-derived peptides produced by $K$. marxianus $\mathrm{Km} 2$ and characterize their antihypertensive effects. For this purpose a K. marxianus LF permeate enriched in peptides of molecular weight lower than $3 \mathrm{kDa}$ ( $\mathrm{pLFH}$ ) was fractionated and the main peptides present in the ACE-inhibitory fractions identified by using an ion trap mass spectrometer. Selected peptides were evaluated for their inhibitory effects on ACE activity, their antihypertensive effects in SHRs and their stability against simulated 
gastrointestinal digestion. Finally the in vivo effect of peptides on SHRs blood ACE activity as well as angiotensin II and aldosterone levels are discussed.

\section{MATERIALS AND METHODS}

Materials. Bovine LF was provided by FrieslandCampina Domo (Zwolle, The Netherlands). ACE from porcine kidney, captopril, and bicinchoninic acid protein assay kit were purchased from Sigma (St. Louis, MO). Glucose was obtained from Panreac (Barcelona, Spain), bacteriological peptone was purchased from Cultimed (Barcelona, Spain) and yeast extract and agar were acquired from Pronadisa (Madrid, Spain). ACE substrate o-aminobenzoylglycyl-pnitrophenylalanylproline was provided by Bachem Feinchemikalien (Bubendorf, Switzerland). Corolase PP (porcine pancreatic extract) was from $A B$ enzymes (Darmstadt, Germany). Diazepam and ketamine were purchased from Roche Farma (Madrid, Spain) and Parke-Davis (Alcobendas, Madrid, Spain), respectively. ACE colorimetric kit was acquired from Bühlmann Laboratories (Schönenbuch, Switzerland). AssayMax Angiotensin II ELISA kit was from AssayPro (Saint Charles, MI) and Coat-A-Count Aldosterone ${ }^{125}$ RIA kit was provided by Siemens Medical Solutions Diagnostics (Los Angeles, CA).

\section{Preparation of K. marxianus Lactoferrin Permeate (pLFH) and Fractionation} by Reversed-Phase High-Performance Liquid Chromatography (RP-HPLC). K. marxianus LF hydrolyzate was prepared as previously described and it was subjected to ultrafiltration through a VivaFlow $503 \mathrm{kDa}$ cut-off polyethersulfone membrane (Vivascience, Sartorius Stedim Biotech, Aubagne, France). Resulting 
permeate $(\mathrm{pLFH})$, enriched in peptides of molecular weight lower than $3 \mathrm{kDa}$ showed an $\mathrm{IC}_{50}$ value of $50.2 \pm 2.7 \mu \mathrm{g} / \mathrm{mL} .{ }^{14}$

Fractionation of pLFH was carried out by RP-HPLC using a Waters system (Waters Corporation, Milford, MA) equipped with a 1525 Binary HPLC pump, a 2996 Photodiode Array Detector and a 717 plus Autosampler in combination with a Fraction Collector III. For this purpose, pLFH was applied to a Prep Nova-Pak ${ }^{\circledR}$ HR C18, $60 \AA$ A $6 \mu \mathrm{m}, 7.8 \times 300 \mathrm{~mm}$ column (Waters). The column was developed at a flow rate of $4 \mathrm{~mL} / \mathrm{min}$. Elution was performed with a linear gradient of solvent B (acetonitrile with $0.05 \%$ TFA) in solvent A (water with $0.05 \%$ TFA) from 0 to $20 \% \mathrm{~B}$ in $70 \mathrm{~min}$. Samples of the whole permeate and the fractions $(20 \mathrm{~mL})$ were freeze-dried and kept at $-20^{\circ} \mathrm{C}$ until reconstitution with distilled water for determination of the protein content and in vitro ACE-inhibitory effect, as explained below.

\section{Peptide Sequencing by Reversed-Phase High-Performance Liquid} Chromatography Tandem Mass Spectrometry (RP-HPLC-MS/MS). RPHPLC-MS/MS analysis of pLFH fractions was performed as described by Sánchez-Rivera et al. ${ }^{15}$ with minor changes. The flow rate was $0.2 \mathrm{~mL} / \mathrm{min}$ and the injection volume $50 \mu \mathrm{L}$. Peptides were eluted using a linear gradient from 0 to $45 \%$ of solvent B (acetonitrile:formic acid; $1,000: 0.1, \mathrm{v} / \mathrm{v}$ ) and $55 \%$ of solvent A (water:formic acid; $1,000: 0.1 \% \mathrm{v} / \mathrm{v}$ ) in $120 \mathrm{~min}$. Data Analysis (version 4.0; Bruker Daltoniks) was used to process and transform spectra to representing mass values. BioTools (version 3.2; Bruker Daltoniks) was used to process the MSn spectra, to perform peptide sequencing and to calculate theoretical masses. 
GenScript Corporation (Piscataway, NJ) wherein they were synthesized by solid phase methods using N-(9-fluorenyl) methoxycarbonyl (Fmoc) chemistry.

In vitro Assay of ACE-Inhibitory Activity. In vitro ACE-inhibitory activity of pLFH fractions and synthetic peptides was measured using the fluorescent method described by Sentandreu and Toldrá ${ }^{16}$ based on the hydrolysis of the internally quenched fluorescent substrate o-aminobenzoylglycyl-pnitrophenylalanylproline by the action of ACE. Protein content of peptide fractions was estimated by the bicinchoninic acid method (BCA) using bovine serum albumin as standard. ${ }^{7}$ Synthetic peptide concentration was based on the dry weight of the peptides.

The $\mathrm{IC}_{50}$ value was defined as the protein/peptide concentration required to inhibit $50 \%$ of the ACE activity, and the value for each experiment was estimated by non-linear regression of the experimental data to a four-parameter logistic curve using the software package SigmaPlot v 10.0 (SPSS Inc., Chicago, IL).

In vivo Assay of Antihypertensive Effect in SHRs. Experimental procedures were conducted in accordance with the Spanish legislation on 'Protection of Animals used for Experimental and other Scientific Purposes' and to the Directives of the European Community on this subject. The study was approved by the 'Ethics Committee for Animal Welfare' of 'La Fe' Hospital to be carried out in its accredited animal research facility. 
Male SHRs weighing 230-330 g (Charles River Laboratories, Barcelona, Spain) were housed in temperature-controlled rooms $\left(23^{\circ} \mathrm{C}\right)$ with $12 \mathrm{~h}$ light/dark cycles and consumed tap water and standard diets ad libitum. To minimize the impact of light cycle and feeding on circadian rhythms of blood pressure, ${ }^{17}$ the experiments started always at the same time in the morning (9:00 a.m.) in fasted computer-assisted Non-Invasive Blood Pressure equipment (LE5001 unit with LE5160R cuff \& transducer, Panlab Harvard Apparatus, Cornellá, Barcelona, Spain). Peptides (up to $10 \mathrm{mg} / \mathrm{kg}$ ) were orally administered by gastric intubation in $650 \mu \mathrm{L}$ of physiological saline. Before the measurements, rats were kept at $37^{\circ} \mathrm{C}$ during 15 min to make the pulsations of the tail artery detectable. The SBP was measured before peptide intake (zero time) and 1, 2, 3, 4 and $24 \mathrm{~h}$ after peptide administration.

\section{In vitro Simulated Gastrointestinal Digestion and Analysis of Digests by RP.}

HPLC. Peptides were subjected to a two-stage simulated gastrointestinal digestion process as previously described. ${ }^{10}$ Briefly, pepsin $(0.2 \mathrm{mg})$ was added to aqueous solutions of peptides $(10 \mathrm{~mL} ; 1 \mathrm{mM})$ adjusted at $\mathrm{pH} 2.0$ using $1 \mathrm{~N} \mathrm{HCl}$ and incubated at $37^{\circ} \mathrm{C}$. After $90 \mathrm{~min}$, the $\mathrm{pH}$ was adjusted to 7.5 adding $10 \mathrm{~mL}$ of 
0.4 M sodium phosphate buffer at $\mathrm{pH}$ 7.5. Corolase PP, a proteolytic enzyme preparation that contains trypsin, chymotrypsin, and amino and carboxypeptidase activities, was added $(0.2 \mathrm{mg})$, and the sample was further incubated at $37^{\circ} \mathrm{C}$ for $150 \mathrm{~min}$. The reaction was stopped by heating at $80^{\circ} \mathrm{C}$ for $10 \mathrm{~min}$ in a water bath, followed by cooling at room temperature. Each sample was stored at $-20^{\circ} \mathrm{C}$ until further analysis by RP-HPLC.

Analysis of gastrointestinal digests was performed in the same RP-HPLC system specified above using a Symmetry C18 column $(4.6 \times 150 \mathrm{~mm}, 5 \mu \mathrm{m}$, Waters) kept at $40^{\circ} \mathrm{C}$. The column was developed at a flow rate of $1 \mathrm{~mL} / \mathrm{min}$. Peptides were eluted with a linear gradient of solvent B (acetonitrile with $0.1 \%$ TFA) in solvent A (water with $0.1 \%$ TFA) from 0 to $40 \%$ in 20 min and detected at $214 \mathrm{~nm}$. Peptides LRP and KLRP were quantified in gastrointestinal digests of DPYKLRP, PYKLRP and YKLRP in accordance to standard curves in water.

\section{Determination of Blood Components of the Renin-Angiotensin System.}

Twenty-two rats were anaesthetized by intraperitoneal injection of $5 \mathrm{mg} / \mathrm{kg}$ diazepam and $100 \mathrm{mg} / \mathrm{kg}$ ketamine. Blood samples were collected from the abdominal aorta to obtain both serum and plasma which were kept frozen at $80^{\circ} \mathrm{C}$ until the determination of ACE activity, angiotensin II and aldosterone levels.

Direct quantitative in vitro determination of ACE activity was carried out by using the Bühlmann ACE colorimetric kit according to the manufacturer's instructions. Briefly, it is a kinetic enzymatic assay in which ACE catalyses the cleavage of the synthetic substrate (FAPGG) into an amino acid derivative and a dipeptide. The kinetic of this cleavage reaction is measured by recording the decrease in absorbance at $340 \mathrm{~nm}$. 

using the AssayMax Angiotensin II ELISA kit according to the manufacturer's instructions. Briefly, this assay employs a quantitative sandwich enzyme immunoassay technique in which a polyclonal antibody specific for angiotensin II is pre-coated onto a microplate. The angiotensin II in standards and samples is sandwiched by the immobilized antibody and biotinylated polyclonal antibody specific for angiotensin II, which is recognized by a streptavidin-peroxidase conjugate. A peroxidase enzyme substrate is added and intensity of developed color is measured.

Quantitative in vitro measurement of aldosterone was carried out by using the Coat-A-Count Aldosterone ${ }^{125}$ I RIA kit according to the manufacturer's instructions. Briefly, it is a solid-phase radioimmunoassay, based on aldosteronespecific antibody immobilized to the wall of the assay tube. ${ }^{125}$-labelled aldosterone competes for a fixed time with aldosterone in the sample for antibody sites.

\section{RESULTS}

Fractionation of $K$. marxianus pLFH: ACE-Inhibitory Activity of Resulting Fractions and Identification of Major Peptides. K. marxianus pLFH was subjected to semi-preparative RP-HPLC and the total chromatogram was divided into 11 fractions which showed $\mathrm{IC}_{50}$ values ranging from 49 to $288 \mu \mathrm{g} / \mathrm{mL}$. The three most active fractions (F6, F7 and F11) with $\mathrm{IC}_{50}$ values of 68,74 and 49 $\mu \mathrm{g} / \mathrm{mL}$, respectively, were analyzed by HPLC-MS/MS and the major peptide components were sequenced (35 peptides on total, Table 1). 

in Table 1) from those identified in fractions F6, F7 and F11 were chemically synthesized. These included four sequences (DGKEDL, ESPQTHY, YKLRP and DPYKLRP) that being among the most abundant in each fraction also fulfilled the common structural features described for many ACE-inhibitory peptides derived from food proteins. ${ }^{18}$ Since the role of specifically C-terminal $\mathrm{P}$ residue in enhancing inhibition has been highlighted in most effective antihypertensive sequences derived from milk proteins, ${ }^{1}$ the peptides PYKLRP and GILRP identified in the most active fraction (F11) were also included in the study despite not being abundant. Interestingly the yeast proteolytic system produced the set $I_{50}$ value corresponded to the tripeptide LRP.

Antihypertensive Effect of LF-Derived Peptides. The antihypertensive effect of the six ACE-inhibitory peptide sequences was characterized in SHRs. Average SBP, measured by the tail-cuff method in awake SHRs, was $200 \pm 1 \mathrm{~mm} \mathrm{Hg}(\mathrm{n}=$ 58). Oral administration of the six LF-derived peptides at $10 \mathrm{mg} / \mathrm{kg}$ induced significant reductions in SBP as shown in Figure 1, together with the lack of effect of oral saline and the antihypertensive effect of captopril $(50 \mathrm{mg} / \mathrm{kg})$. Similar to 
241 the effect caused by captopril, the antihypertensive effect of sequences DPYKLRP, GILRP and LRP remained significant up to $24 \mathrm{~h}$ post administration. Antihypertensive effects ranged from $-26.8 \mathrm{~mm} \mathrm{Hg}$ for both DPYKLRP and LRP till $-13.2 \mathrm{~mm} \mathrm{Hg}$ for KLRP. Reductions in SBP caused by DPYKLRP $(-26.8 \pm 2.4$ $\mathrm{mm} \mathrm{Hg} ; 1 \mathrm{~h}$ post administration) and $\operatorname{LRP}(-26.8 \pm 1.3 \mathrm{~mm} \mathrm{Hg} ; 2 \mathrm{~h})$ were comparable to that of the captopril control $(-27.9 \pm 2.1 \mathrm{~mm} \mathrm{Hg} ; 1 \mathrm{~h})$ (one-way ANOVA; $P>0.05)$. The heptapeptide DPYKLRP and the tripeptide LRP were further studied for dose-dependent antihypertensive effects. Both peptides induced significant dose-dependent $(3,7$ and $10 \mathrm{mg} / \mathrm{kg})$ reductions in SBP at each time point from 1 $\mathrm{h}$ to $24 \mathrm{~h}$ after oral administration (Figure 2).

252

Resistance of LF-Derived Peptides to Gastrointestinal Enzymes. The six antihypertensive peptides were subjected to a hydrolysis process which simulates gastrointestinal digestion due to the action of gastric and pancreatic enzymes. The analysis of digests by RP-HPLC (Figure 3) showed that the longer sequences, DPYKLRP and PYKLRP, were completely hydrolyzed releasing several fragments. A partial hydrolysis was observed for the pentapeptide YKLRP (approximately $60 \%$ of the initial concentration of the input peptide). In the conditions tested, sequences KLRP and GILRP were slightly hydrolyzed (approximately $6 \%$ and $12 \%$ decrease from the initial concentrations) whereas LRP was resistant to gastrointestinal enzymes. Noteworthy, in the gastrointestinal digests of the hydrolyzed peptides, the sequences LRP and KLRP were detected among others. LRP at concentrations of $525 \mu \mathrm{M}, 600 \mu \mathrm{M}$ and $465 \mu \mathrm{M}$ were detected in the digests of DPYKLRP, PYKLRP and YKLRP, 
respectively. Also a minor quantity of LRP $(3 \mu \mathrm{M})$ was detected in the KLRP digest. In the conditions tested, the sequence LRP was not detected in the GILRP digest. With respect to KLRP, concentrations of $550 \mu \mathrm{M}$ and $140 \mu \mathrm{M}$ were detected in the digests of DPYKLRP and PYKLRP. Also the sequence KLRP was detected at a concentration of $17 \mu \mathrm{M}$ in the YKLRP digest.

\section{Effects of LF-Derived Peptides on Blood Components of the Renin-} Angiotensin System. The effects of DPYKLRP and LRP (10 mg/kg) on serum ACE activity and angiotensin II levels, and on plasma aldosterone levels were studied in SHRs. Captopril (50 mg/kg) was also included as a positive control.

The average serum ACE activity for all measurements carried out in the three experimental groups before treatment intake was $111.4 \pm 1.8 \mathrm{U} / \mathrm{L}(\mathrm{n}=22)$. As shown in Figure 4A, ACE activity was significantly reduced in SHRs treated with DPYKLRP, LRP and captopril at $1 \mathrm{~h}$ and $4 \mathrm{~h}$ post administration, and reverted to initial values after $24 \mathrm{~h}$. At $1 \mathrm{~h}$ post administration, when maximum effects were observed, the reduction in ACE activity induced by DPYKLRP (48.1 $\pm 2.5 \%)$ was similar to that caused by captopril $(43.4 \pm 3.1 \%)$, and significantly higher than the reduction induced by LRP $(19.1 \pm 2.7 \%)$ in SHRs (one way ANOVA followed by Student-Newman-Keuls test).

SHRs showed an average serum angiotensin II level of $71.2 \pm 1.3 \mathrm{pg} / \mathrm{mL}$ $(n=22)$ before treatment intake. Angiotensin II levels in SHRs were significantly reduced by the three treatments at $1 \mathrm{~h}$ post administration (Figure 4B). The effect of LRP reverted at $4 \mathrm{~h}$ post administration whereas the reductions caused by the heptapeptide and captopril reverted at $24 \mathrm{~h}$. When maximum effects were observed $(1 \mathrm{~h})$, the effects caused by DPYKLRP $(27.1 \pm 0.6 \%$ reduction in 
angiotensin II levels) and captopril $(33.2 \pm 1.3 \%)$ were similar and higher than that provoked by LRP treatment to SHRs $(14.8 \pm 1.9 \%$; one way ANOVA followed by Student-Newman-Keuls test).

By contrast to that observed in serum ACE activity and angiotensin II levels, plasma aldosterone level of SHRs $(244.7 \pm 1.9 \mathrm{pg} / \mathrm{mL} ; \mathrm{n}=22)$ was not significantly affected by any of the treatments (data not shown).

\section{DISCUSSION}

Yeast products have been used for many years as ingredients and additives in food processing, although their potential bioactivity has been less investigated. ${ }^{19}$ K. marxianus, considered a GRAS (Generally Recognized As Safe) microorganism, has been isolated from a great variety of habitats, which results in a high metabolic diversity. Therefore, different biotechnological applications of this yeast including production of enzymes, of single cell-protein, and of aroma compounds as well as production of bioingredients from cheesewhey have been described ${ }^{20}$ Moreover the beneficial properties of $K$. marxianus as a human probiotic have been recently assessed. ${ }^{21}$

In this study, we have identified four novel LF-derived peptides which are reported as ACE-inhibitory and antihypertensive sequences for the first time. To the best of our knowledge, DPYKLRP, PYKLRP, YKLRP and GILRP produced by the proteolytic system of $K$. marxianus $\mathrm{Km} 2$ strain when grown in LF as sole nitrogen source, are the first peptides with antihypertensive effects after oral administration to SHRs produced by a food-isolated yeast strain. Novel sequences identified here could at least in part contribute to the ACE inhibiting and antihypertensive effects of $K$. marxianus pLFH. ${ }^{14}$ 

residue. It has been described that the rigid structure of this amino acid may lock the carboxyl group into a conformation favorable for interaction with the positively charged residue at the active site of the enzyme. ${ }^{22}$ Also the four sequences share the C-terminal tripeptide LRP. Interestingly LRP, which can be found in three different regions of LF sequence, was pointed out as the sequence responsible of the in silico high ACE-inhibitory activity of different peptide sequences in LF, and in accordance with our results, an $\mathrm{IC}_{50}$ value of $0.27 \mu \mathrm{M}$ was described for the tripeptide. ${ }^{12}$ The sequence LIWKL was the most potent LF-derived peptide described so far $\left(\mathrm{IC}_{50}=0.47 \pm 0.01 \mu \mathrm{M}\right) .{ }^{8}$ Here, LRP was the most potent sequence with an $\mathrm{IC}_{50}$ value $\left(\mathrm{IC}_{50}=0.35 \pm 0.03 \mu \mathrm{M}\right)$ slightly lower than that of LIWKL. Our results suggest that $\mathrm{N}$-terminal elongations decrease in vitro inhibitory potency, although it might not result in lower antihypertensive effects (see below). Moreover elongations at the C-terminal end of the tripeptide also inhibitory potency and the in vivo antihypertensive effects after oral administration of the digests suggesting that the tripeptide might contribute to the in vivo effects 
relevance of LRP as well as of the other digestion fragments that could also contribute to the blood pressure-lowering effects of parental peptides.

Although the $\mathrm{IC}_{50}$ values of LF-derived peptides were by far higher than that of ACE-inhibitory drug captopril $(0.022 \mu \mathrm{M}),{ }^{24}$ in the conditions tested, oral administration of DPYKLRP and LRP resulted in a significant decrease in SBP (13.4\% reduction from baseline) similar to that of captopril (14\% reduction). These results are also in agreement with the previously reported antihypertensive effect of the LF-derived peptide LIWKL (12.1\% reduction). ${ }^{8}$ It has been reported that food-derived ACE-inhibitory peptides might possess higher in vivo effects than expected from in vitro inhibitory potencies due to their higher affinity to target tissues and their slower elimination. ${ }^{25}$

It has been also postulated that other mechanisms of action apart from ACE inhibition might underlie in vivo antihypertensive effect of ACE-inhibitory peptides, including short-term vasoactive mechanisms as well as long termantioxidant and anti-inflammatory mechanisms ${ }^{26}$ In this context the sequence GILRP isolated here is part of the sequences GILRPY and GILRPYL identified in a proteinase K LF hydrolyzate which exerted in vivo antihypertensive effect. Both the hydrolyzate and GILRPY showed significant endothelin converting enzyme (ECE)-inhibitory effects. ${ }^{9} \mathrm{ECE}$ is a key peptidase in the endothelin system that cleaves precursor inactive big endothelin-1 to produce active endothelin-1 which has powerful vasoconstrictor and pressor properties. ${ }^{27}$ The endothelin system has an increasingly recognized role in blood pressure regulation, and has also been targeted for hypertension drug treatment. Moreover, we described a set of peptides derived from LF which showed inhibitory effects on ACE and ECE activities ${ }^{28}$ Also the ACE-inhibitory peptide lactokinin can modulate endothelin-1 
release by endothelial cells. ${ }^{29}$ Whether the antihypertensive effect showed by GILRP in this study might be also due to ECE inhibition deserves further studies. Dose-dependent antihypertensive effects of DPYKLRP and LRP prompted us to look for a mechanism of action responsible for the graded in vivo responses of the LF-derived peptides. Determinations of blood RAS components support ACE inhibition as an in vivo antihypertensive mechanism in SHRs. In vivo ACEinhibitory effect can be assessed by measuring tissue membrane-anchored or soluble, circulating ACE activities, and confirmed by measuring circulating levels of angiotensin II. ${ }^{30}$ Our results show that serum ACE activity is reduced in SHRs after oral administration of both peptides. Moreover, inhibition of ACE was confirmed in peptide treated SHRs by the reduction in angiotensin II level. We have previously reported that long term administration to SHRs of an antihypertensive bovine LF pepsin hydrolyzate enriched in low molecular weight peptides reduced circulating ACE activity, angiotensin II and aldosterone levels. ${ }^{10}$ By contrast, in the present study, the level of serum aldosterone, the adrenal endocrine component downstream angiotensin II in the renin-angiotensin axis, ${ }^{2}$ was not affected by single-dose treatments with DPYKLRP and LRP. In vivo ACE inhibition has been also pointed out as the mechanism underlying the blood pressure reduction of the tripeptide IQP derived from the blue algae Spirulina platensis since serum ACE and angiotensin II levels were significantly reduced in SHRs after one-week treatment. ${ }^{31}$ Nonetheless, the identification of other in vivo mechanisms beyond ACE inhibition underlying antihypertensive effects of the LFderived peptides identified in this study should be further investigated.

Our results point out $K$. marxianus as a feasible GRAS microorganism for the production of novel LF-derived peptides with ACE-inhibitory and 
antihypertensive effects. The LF-derived peptides produced by $K$. marxianus, DPYKLRP, PYKLRP, YKLRP and GILRP, effectively decreased arterial blood pressure in SHRs and could, at least in part be responsible for the antihypertensive properties previously described for $K$. marxianus LF hydrolyzate. Also data reported here suggest ACE inhibition as in vivo mechanism for the antihypertensive effects of the sequences DPYKLRP and LRP in particular, although other mechanisms cannot be discarded.

397 recognized as safe; $L A B$, lactic acid bacteria; $p L F H$, lactoferrin permeate enriched in peptides of molecular weight lower than $3 \mathrm{kDa}$; RAS, reninangiotensin system; RP-HPLC, reversed-phase high-performance liquid chromatography; RP-HPLC-MS/MS, reversed-phase high-performance liquid chromatography tandem mass spectrometry; SBP, systolic blood pressure; SHRs, spontaneously hypertensive rats; TFA, trifluoroacetic acid.

407

\section{ACKNOWLEDGEMENT}

The authors thank José Javier López-Díez and Sonia Ruiz-Piquer for technical assistance. 
(1) Martínez-Maqueda, D.; Miralles, B.; Recio, I.; Hernández-Ledesma, B.

414 Antihypertensive peptides from food proteins: a review. Food \& Function 2012 , $4153,350-361$.

(2) Carey, R. M.; Siragy, H. M. (2003). Newly recognized components of the renin-angiotensin system: potential roles in cardiovascular and renal regulation. Endocrine Rev. 2003, 24, 261-271.

419

(3) Vermeirssen, V.; van Camp, J.; Verstraete, W. Bioavailability of angiotensin I converting enzyme inhibitory peptides. Br. J. Nutr. 2004, 92, 357-366.

421

(4) Turpeinen, A. M.; Järvenpää, S.; Kautiainen, H.; Korpela, R.; Vapaatalo, H.

Antihypertensive effects of bioactive tripeptides-random effects meta-analysis. Ann. Med. 2013, 45, 51-56.

424

(5) Hernández-Ledesma, B.; Contreras, M.M.; Recio, I. Antihypertensive 425 peptides: production, bioavailability and incorporation into foods. Adv. Coll. Int. Sci. 2011, 165, 23-35.

(6) Hamme, V.; Sannier, F.; Piot, J.-M.; Didelot, S.; Bordenave-Juchereau, S.

Crude goat whey fermentation by Kluyveromyces marxianus and Lactobacillus rhamnosus: contribution to proteolysis and ACE inhibitory activity. J. Dairy Res. 2009, 76, 152-157.

431

(7) Chaves-López, C.; Tofalo, R.; Serio, A.; Paparella, A.; Sacchetti, G.; Suzzi,

G. Yeasts from colombian Kumis as a source of peptides with angiotensin-I converting enzyme (ACE) inhibitory activity in milk. Int. J. Food Microbiol. 2012, 159, 39-46.

435

(8) Ruiz-Giménez, P.; Salom, J. B.; Marcos, J. F.; Vallés, S., Martínez-Maqueda, 
437 of a bovine lactoferrin pepsin hydrolysate: identification of novel active peptides.

438 Food Chem. 2012, 131, 266-273.

439 (9) Fernández-Musoles, R.; Salom, J. B.; Martínez-Maqueda, D.; López-Díez,

J. J.; Recio, I.; Manzanares, P. Antihypertensive effects of lactoferrin hydrolysates: inhibition of angiotensin- and endothelin-converting enzymes. Food Chem. 2013 139, 994-1000.

(10) Fernández-Musoles, R.; Manzanares, P.; Burguete, M. C.; Alborch, E;

444 Salom J. B. In vivo angiotensin I-converting enzyme inhibition by long-term intake of antihypertensive lactoferrin hydrolysate in spontaneously hypertensive rats. Food Res. Int. 2013, 54, 627-632.

(11) Ruiz-Giménez, P.; Ibáñez, A.; Salom, J. B.; Marcos, J. F.; López-Díez, J.

J.; Vallés, S.; Torregrosa, G.; Alborch, E.; Manzanares, P. Antihypertensive properties of lactoferricin B-derived peptides. J. Agric. Food Chem. 2010, 58, $6721-6727$.

451

(12) Vermeirssen, V.; van der Bent, A.; van Camp, J.; van Amerongen, A.;

Verstraete, W. A quantitative in silico analysis calculates the angiotensin I converting enzyme (ACE) inhibitory activity in pea and whey protein digests.

454 Biochim. 2004, 86, 231-239.

455

(13) Padilla, B.; Manzanares, P.; Belloch, C. (2014). Yeast species and genetic 456 heterogeneity within Debaryomyces hansenii along the ripening process of 457 traditional ewes' and goats' cheeses. Food Microbiol. 2014, 38, 160-166.

458 (14) García-Tejedor, A.; Padilla, B.; Salom, J. B.; Belloch, C.; Manzanares, P. 459 Dairy yeasts produce milk protein-derived antihypertensive hydrolysates. Food 460 Res. Int. 2013, 53, 203-208. 
(15) Sánchez-Rivera, L.; Recio, I.; Ramos; M.; Gómez-Ruiz, J. A. Peptide

462

463

464

465

466

467

468

469

470

471

472

473

474

475

476

477

478

479

480

481

482 483

profiling in cheeses packed using different technologies. J. Dairy Sci. 2013, 96, 3551-3557.

(16) Sentandreu, M. A.; Toldrá, F. A rapid, simple and sensitive fluorescence method for the assay of angiotensin-I converting enzyme. Food Chem. 2006, 97, 546-554.

(17) van den Buuse, M. Circadian rhythms of blood pressure and heart rate in conscious rats: effects of light cycle shift and timed feeding. Physiol. Behav. 1999, 68, 9-15.

(18) Murray, B. A.; FitzGerald, R. J. Angiotensin converting enzyme inhibitory peptides derived from food proteins: biochemistry, bioactivity and production. Curr. Pharm. Des. 2007, 13, 773-791.

(19) Abbas, C. A. (2006). Production of antioxidants, aromas, colours, flavours and vitamins by yeasts. In Yeasts in food and beverages; Querol, A., Fleet, G. H., Eds.; Springer: New York, NY, 2006; pp. 285-334.

(20) Fonseca, G. G.; Heinzle, E.; Wittmann, C.; Gombert, A. K. The yeast Kluyveromyces marxianus and its biotechnological potential. Appl. Microbiol. Biotechnol. 2008, 79, 339-354.

(21) Maccaferri, S.; Klinder, A.; Brigidi, P.; Cavina, P.; Costabile, A. Potential probiotic Kluyveromyces marxianus B0399 modulates the immune response in Caco-2 cells and peripheral blood mononuclear cells and impacts the human gut microbiota in an in vitro colonic model system. App. Environ. Microbiol. 2012, 78, 956-964. 
(22) Cushman, D. W.; Cheung, H. S.; Sabo, E. F.; Ondetti, M. A. Design of

485

486

487

488

489

490

491

492

493

494

495

496

497

498

499

500

501

502

503

504

505

506

507

potent competitive inhibitors of angiotensin-converting enzyme. Carboxyalkanoyl and mercaptoalkanoyl amino acids. Biochem. 1977, 16, 5484-5491.

(23) Lee, N-Y.; Cheng, J-T.; Enomoto, T.; Nakamura, I. The antihypertensive activity of angiotensin-converting enzyme inhibitory peptide containing in bovine lactoferrin. Chin. J. Physiol. 2006, 49, 67-73.

(24) Ondetti, M. A.; Rubin, B.; Cushman, D. W. Design of specific inhibitors of angiotensin-converting enzyme: new class of orally active antihypertensive agents. Science 1977, 196, 441-444.

(25) Fujita, H.; Yoshikawa, M. LKPNM: a pro-drug type ACE-inhibitory peptide derived from fish protein. Immunopharmacol. 1999, 44, 123-127.

(26) Marques, C.; Amorim, M.M.; Pereira, J.O.; Pintado, M.E.; Moura, D.; Calhau, C.; Pinheiro, H. Bioactive peptides: are there more antihypertensive mechanisms beyond ACE inhibition? Curr. Pharm. Des. 2012, 18, 4706-4713.

(27) Schiffrin, E. L. Vascular endothelin in hypertension. Vasc. Pharmacol. 2005, $43,19-29$.

(28) Fernández-Musoles, R.; López-Díez, J. J.; Torregrosa, G.; Vallés, S.; Alborch, E.; Manzanares, P.; Salom J. B. Lactoferricin B-derived peptides with inhibitory effects on ECE-dependent vasoconstriction. Peptides 2010, 31, 19261933.

(29) Maes W.; van Camp J.; Vermeirssen V.; Hemeryck M.; Ketelslegers J. M.; Schrezenmeir J.; van Oostveldt, P.; Huyghebaert, A. Influence of the lactokinin Ala-Leu-Pro-Met-His-Ile-Arg (ALPMHIR) on the release of endothelin-1 by endothelial cells. Reg. Peptides 2004, 118, 105-109. 
508 (30) Coates, D. The angiotensin converting enzyme (ACE). Int. J. Biochem. Cell 509 Biol. 2003, 35, 769-773.

510 (31) Lu, J.; Sawano, Y.; Miyakawa, T.; Xue, Y-L.; Cai, M-Y.; Egashira, Y.; Ren,

511 D-F.; Tanokura, M. One-week antihypertensive effect of Ile-Gln-Pro in

512 spontaneously hypertensive rats. J. Agric. Food Chem. 2011, 59, 559-563.

513

514 FUNDING

515 This work was supported by grant AGL2010-21009 from 'Ministerio de Educación

516 y Ciencia - FEDER', Consolider Ingenio 2010, Fun-ㅡ-Food, CSD2007-00063 and

517 RETICS INVICTUS RD12/0014/0004 from 'Instituto de Salud Carlos III'. A.

518 García-Tejedor is recipient of a predoctoral fellowship from 'Ministerio de 519 Educación y Ciencia' (BES-2011-044424).

520 


\section{Figure captions}

522 Figure 1. Time course of systolic blood pressure (SBP) changes after oral 523 administration of physiological saline, captopril (50 mg/kg) and LF-derived 524 peptides $(10 \mathrm{mg} / \mathrm{kg})$ to $S H R s$. Pressure changes $(\triangle S B P)$ are expressed in 525 absolute values $(\mathrm{mm} \mathrm{Hg})$ and data are expressed as mean \pm SEM from 6-7 526 determinations. ${ }^{*} P<0.01$ versus control saline group (one-way ANOVA followed 527 by Dunnett multiple comparison tests).

528 Figure 2. Time course of systolic blood pressure (SBP) changes after oral 529 administration of increasing doses of DPYKLRP $(A)$ and LRP $(B)$ to SHRs. $(O)$ 530 physiological saline, (A) $3 \mathrm{mg} / \mathrm{kg},(\mathbf{\square}) 7 \mathrm{mg} / \mathrm{kg},(\mathbf{O}) 10 \mathrm{mg} / \mathrm{kg}$. Pressure changes are expressed in absolute values $(\mathrm{mm} \mathrm{Hg})$ and data are expressed as mean \pm SEM from 5-8 determinations. Different letters indicate significant differences among doses at each time point (one-way ANOVA followed by Student-NewmanKeuls multiple comparison tests, $P<0.05)$.

Figure 3. RP-HPLC chromatograms of peptides before (dashed line) and after 536 (solid line) being submitted to a simulated gastrointestinal digestion. (A) DPYKLRP, (B) PYKLRP, (C) YKLRP, (D) KLRP, (E) LRP, (F) GILRP.

Figure 4. Time course of changes produced in the levels of blood components of the renin-angiotensin system after oral administration of DPYKLRP (10 mg/kg),

540 LRP (10 mg/kg) and captopril (50 mg/kg) to SHRs. (A) Serum angiotensin Iconverting enzyme (ACE) activity. (B) Serum angiotensin II levels. Data are mean \pm SEM from $4-10$ determinations. ${ }^{*} P<0.05$ versus baseline values at time $0 \mathrm{~h}$, ${ }^{* *} P<0.01$ versus baseline values at time $0 \mathrm{~h}$ (one-way ANOVA followed by

544 Dunnett multiple comparison tests). 
Table 1. Identification of Peptides Contained in the F6, F7 and F11 RP-HPLC

Fractions of the K. marxianus Lactoferrin Permeate (pLFH)

\begin{tabular}{|c|c|c|c|c|c|}
\hline fraction $^{a}$ & $\begin{array}{l}\text { ion for MS/MS } \\
(\mathrm{m} / \mathrm{z})^{b}\end{array}$ & $\begin{array}{c}\text { observed } \\
\text { mass }^{c}\end{array}$ & $\begin{array}{c}\text { theoretical } \\
\text { mass }\end{array}$ & $\begin{array}{l}\text { protein } \\
\text { fragment }\end{array}$ & $\begin{array}{l}\text { identified } \\
\text { sequence }\end{array}$ \\
\hline \multirow[t]{10}{*}{ F6 } & 755.397 & 754.390 & 754.372 & $f(601-607)$ & SDRAAHV \\
\hline & 779.362 & 778.354 & 778.361 & $f(652-658)$ & GGRPTYE \\
\hline & 646.390 & 645.382 & 645.333 & $f(335-340)$ & AEEVKA \\
\hline & 676.329 & 675.322 & 675.308 & $f(261-266)$ & DGKEDL $^{d}$ \\
\hline & 624.367 & 623.360 & 623.303 & $f(283-287)$ & SRSFQ \\
\hline & 638.438 & 637.431 & 637.355 & $f(611-615)$ & LLHQQ \\
\hline & 668.412 & 667.405 & 667.340 & $f(602-607)$ & DRAAHV \\
\hline & 607.349 & 606.341 & 606.276 & $f(68-72)$ & GRDPY \\
\hline & 439.113 & 438.105 & 438.211 & $f(319-322)$ & YLGS \\
\hline & 722.407 & 721.400 & 721.376 & $f(276-281)$ & EKFGKN \\
\hline \multirow[t]{13}{*}{$\mathrm{F} 7$} & 908.426 & 907.419 & 907.404 & $f(652-659)$ & GGRPTYEE \\
\hline & 575.214 & 574.206 & 574.260 & $f(536-541)$ & DVGDVA \\
\hline & 714.516 & 713.509 & 713.480 & $f(435-441)$ & AVAVVKK \\
\hline & 775.417 & 774.409 & 774.376 & $f(260-266)$ & VDGKEDL \\
\hline & 504.075 & 503.068 & 503.223 & $f(536-540)$ & DVGDV \\
\hline & 851.407 & 850.400 & 850.382 & $f(653-659)$ & GRPTYEE \\
\hline & 548.256 & 547.249 & 548.226 & $f(503-508)$ & ALCAGD \\
\hline & 636.454 & 635.447 & 635.375 & $f(338-342)$ & VKARY \\
\hline & 582.226 & 581.219 & 581.270 & $f(660-664)$ & YLGTE \\
\hline & 572.331 & 571.324 & 571.333 & $f(28-33)$ & KLGAPS \\
\hline & 496.155 & 495.148 & 495.244 & $f(283-286)$ & SRSF \\
\hline & 779.466 & 778.459 & 778.434 & $f(98-104)$ & VKKGSNF \\
\hline & 861.351 & 860.344 & 860.366 & $f(86-92)$ & ESPQTHY $^{d}$ \\
\hline \multirow[t]{12}{*}{ F11 } & 848.427 & 847.420 & 847.455 & $f(68-74)$ & GRDPYKL \\
\hline & 823.472 & 822.465 & 822.387 & $f(224-229)$ & RDQYEL \\
\hline & 693.239 & 692.232 & 692.281 & $f(189-194)$ & YFGYSG \\
\hline & 743.382 & 742.375 & 742.386 & $f(141-147)$ & SLEPLQG \\
\hline & 773.499 & 772.492 & 772.460 & $f(71-76)$ & PYKLRP $^{d}$ \\
\hline & 907.415 & 906.408 & 906.420 & $f(563-569)$ & NLNREDF \\
\hline & 780.312 & 779.305 & 779.345 & $f(101-107)$ & GSNFQLD \\
\hline & 677.293 & 676.286 & 676.318 & $f(445-450)$ & GLTWNS \\
\hline & 676.510 & 675.503 & 675.407 & $f(72-76)$ & YKLRP $^{d}$ \\
\hline & 555.428 & 554.421 & 554.354 & $f(130-134)$ & GILRP $^{d}$ \\
\hline & 888.482 & 887.475 & 887.487 & $f(70-76)$ & DPYKLRP $^{d}$ \\
\hline & 414.156 & 413.149 & 413.227 & $f(144-147)$ & PLQG \\
\hline
\end{tabular}

aFractions are termed as in Figure 1.

${ }^{b}$ Charge of precursor ion: 1

${ }^{c}$ Calculated monoisotopic mass

${ }^{d}$ Chemically synthesized peptides are labelled in bold. 
Table 2. Inhibitory Potency of Selected LF-Derived Peptides on ACE Activity

\begin{tabular}{|c|c|}
\hline peptide & $\mathrm{IC}_{50}(\mu \mathrm{M})^{a}$ \\
\hline DPYKLRP & $30.5 \pm 1.4$ (c) \\
\hline PYKLRP & $10.2 \pm 1.2(b)$ \\
\hline YKLRP & $16.5 \pm 0.7(b)$ \\
\hline KLRP & $91.6 \pm 4.0(d)$ \\
\hline $\mathrm{LRP}$ & $0.35 \pm 0.03(\mathrm{a})$ \\
\hline GILRP & $90.7 \pm 5.0(d)$ \\
\hline
\end{tabular}


Figure 1
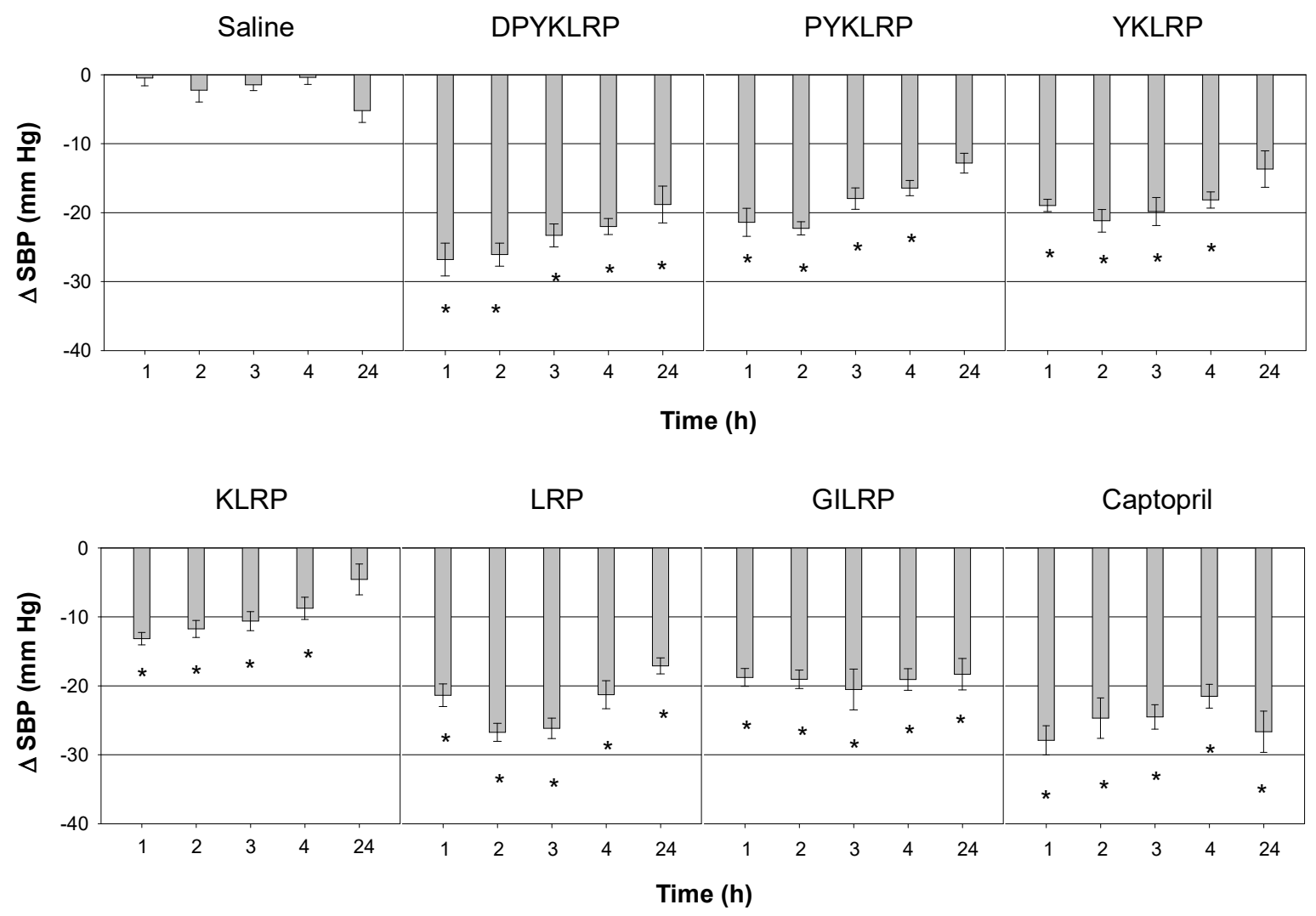
Figure 2

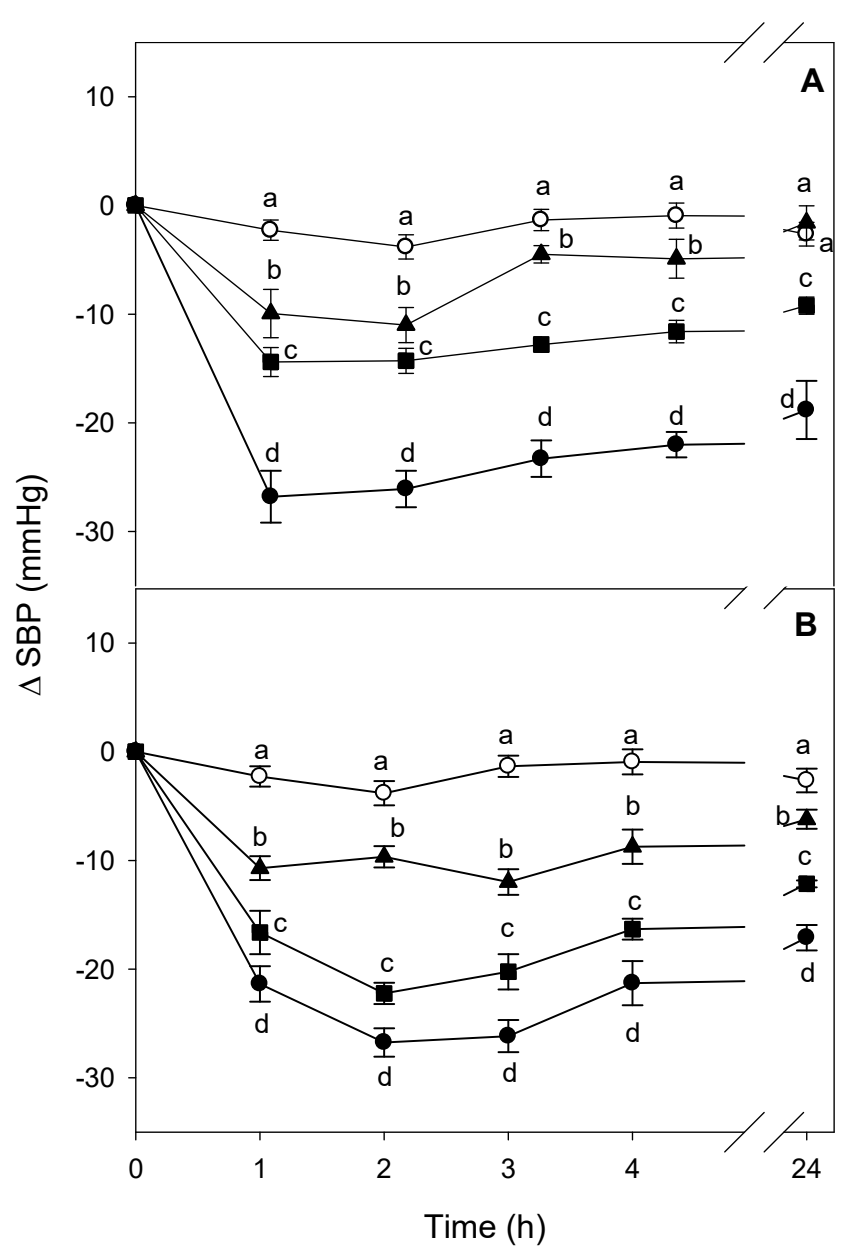

549 
Figure 3
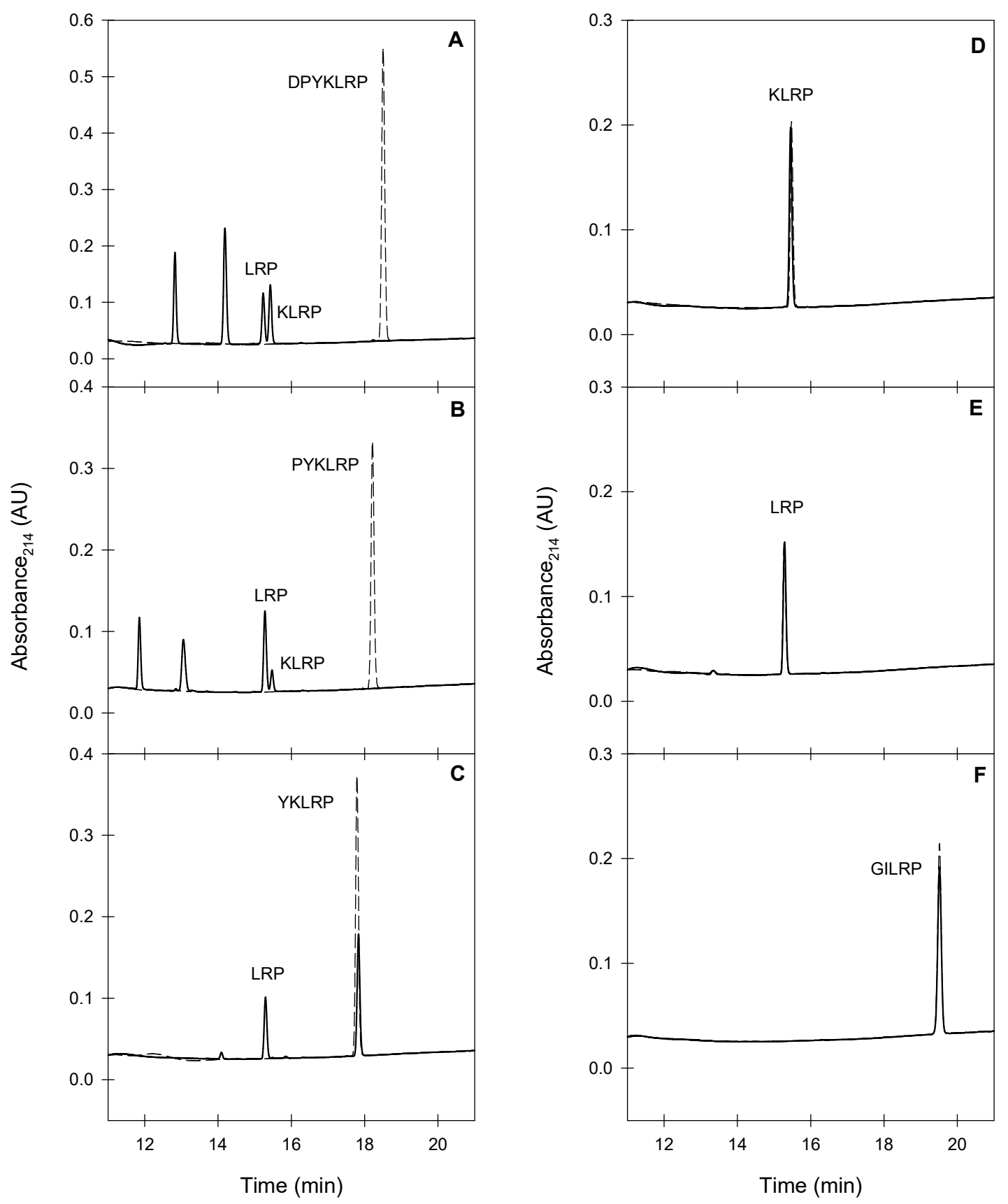
Figure 4

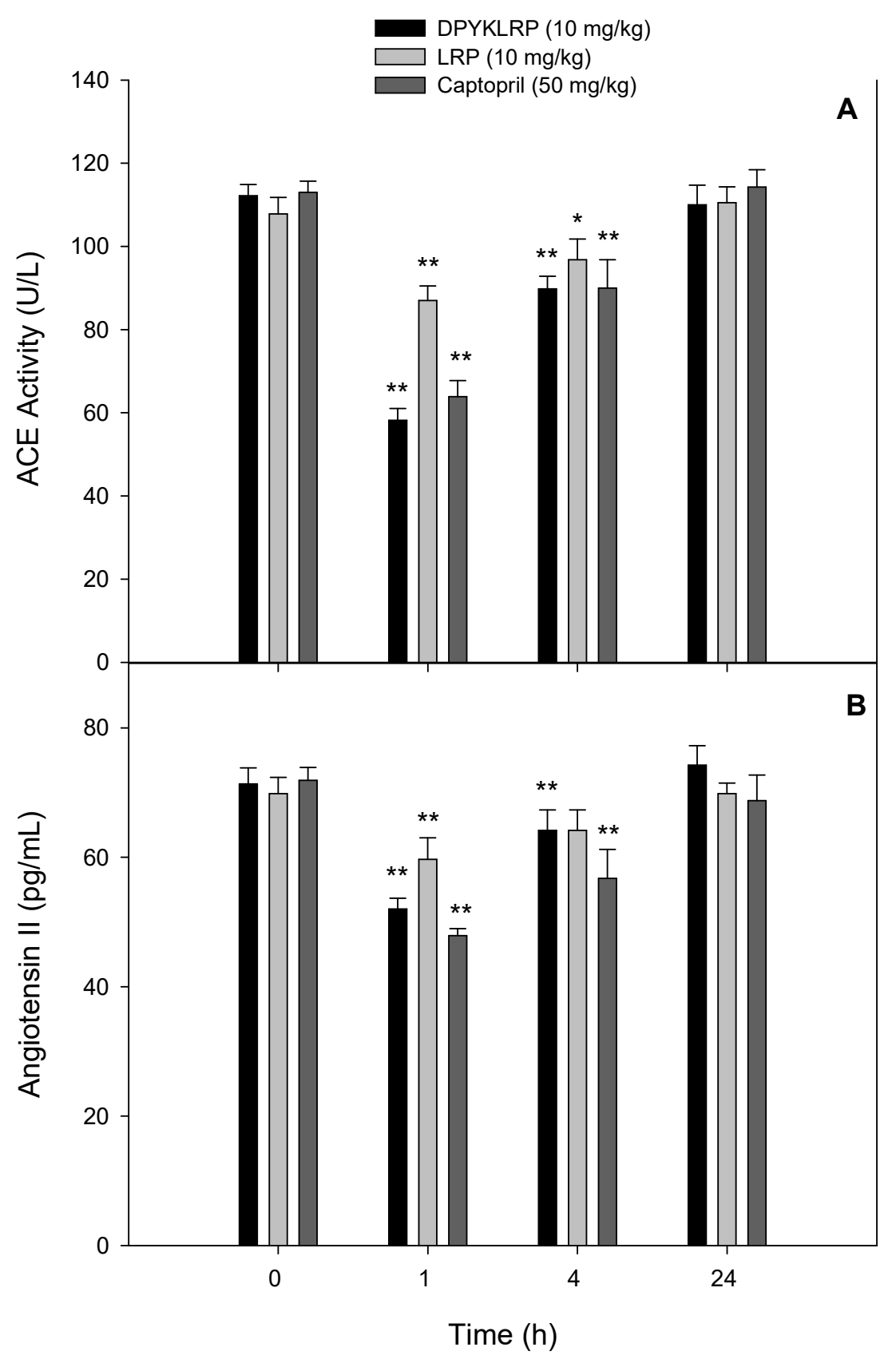

